\title{
SOMETIMES STUDENTS MAKE THE BEST TEACHERS: DEVELOPING AND ENHANCING GRADUATE SKILLS
}

\author{
Ann Gow \\ Information Studies, University of Glasgow (United Kingdom)
}

\begin{abstract}
This paper will provide a discussion and demonstration of an experimental implementation of a new approach to fostering graduate skills and enhancing the learning experience of final year's students in Digital Media and Information Studies (DMIS), an undergraduate degree at the University of Glasgow. Teaching staff in the subject area worked collaboratively with students in a Peer Assisted Learning (PAL) study to develop a training programme for student demonstrators for the computer-based lab sessions that are a requirement in the DMIS level 1 courses. The process enabled the development of training in practical and critical thinking skills for the students, and developed a two-way process of mentoring and feedback that allowed both staff and students to learn from the process. The evaluation of the programme has indicated that involvement in this project has had a number of positive outcomes for students. Most significantly, it has enhanced and developed student graduate attributes, making a contribution to an excellent student experience. This initiative used existing methods in peer learning, and built on research such as Student Peer Learning \& The AALL Professional Evolution, Equity \& innovation Students Supporting Student Learning (SSSL) Symposium 2012.

This paper will be delivered by teaching staff involved in the project, supported with video contribution from students taking part in the scheme as supporting evidence of their experience of the effectiveness of the activity on student learning experiences and employability beyond graduation. Evaluation at the end of the project evidences the positive effect for both sets of students, with qualitative feedback overwhelmingly positive.

The University of Glasgow has developed Graduate Attributes as a core objective of student learning: "core attributes are valued and developed across academic, social and professional settings". This paper will reflect on the success of embedding defined UofG Graduate Attributes into this scheme: these include Subject Specialist, Confident, Effective Communicators, and Resourceful, and Responsible. Our project, has shown that these attributes are achieved not only through the classroom activities but also through application of training and accreditation, from participation in UofG GTA training, Subject meetings, and support to apply for UofG accredited Recognising Excellence in Teaching (RET) scheme. This in turn is aligned to Charted Institute for Library and Information Professionals (CILIP) professional accreditation for the single honours DMIS degree, ensuring our demonstrators graduate with a firm set of graduate attributes and employability skills.
\end{abstract}

Keywords: Cooperative learning, peer teaching, undergraduate, graduate attributes, educational benefits.

\section{Context}

The Department of Information Studies at the University of Glasgow has a long and distinguished history in a number of significant areas of Information Studies, with particular expertise in digital curation, research data and information management, museum studies, and digital heritage. Information Studies has a unique undergraduate degree in Digital Media and Information Studies, accredited by the Chartered Institute of Librarians and Information Professionals (CILIP) that has grown significantly in numbers in the last two years.

We offer what is known in Scotland as a Single honours in Digital Media and Information Studies in the College of Arts (MA) and also a Joint MA degree in with another subject from the College of Arts or Social Sciences. Students enrolled on these programmes study over four years, following a broad curriculum in their first two years, with Digital Media and Information Studies contributing 33\% of their Level 1 curriculum and 33\% of their Level 2 curriculum. In their 3rd and 4th year, they focus on one subject (single honours) or two subjects (joint honours). Students graduate with an MA, a degree awarded by the four ancient Scottish Universities. 


\section{Subject coverage}

We focus our teaching on the connection between the Information Age, information studies, and digital media. Digital media - i.e. media that can be created, viewed, distributed, modified and preserved on digital electronic devices through encoding in machine-readable formats - epitomise the transition from the Industrial to the Information Age. In combination with the internet and World Wide Web, digital media represent the means to access the digital universe of opportunities and challenges. Within information studies, the entire lifecycle of digital media becomes the subject of study and analysis.

\subsection{Challenge}

The practicality of delivering this curriculum is to present the theory through traditional lectures and for the students to learn in smaller class sizes through practice, group work and reflection in a computer lab environment. We had established a fairly small Peer Assisted Learning group for final year students that met informally with 1st year students and we decided to expand this PAL system to create lab demonstrator internships. The objective was to empower students to do the following: to lead lab sessions in subject specialism on the demonstration of DMIS level 1; to support teaching through the demonstration of exercises in line with agreed learning outcomes of the course; to lead sessions on DMIS and to oversee students carrying out practical exercises; and offer assistance, as appropriate, including the provision of detailed explanations of how the activity related to the wider area of study.

We have a University-wide commitment to develop our students' graduate attributes across the curriculum. The PAL (Arendale 2014) lab demonstrator scheme therefore gives senior honours students the opportunity to develop and enhance graduate attributes through employment as a lab demonstrator. This role enables them to provide a valuable support mechanism for DMIS level 1 students via technical support as well as offering wider peer-to-peer support.

\section{PAL Schemes}

We developed this internship role, designed to support both the final year and first year students, given the context that final year students will from a network (Arendale 2014) with Information Studies staff delivering Level 1 course. This network is first port of call for other opportunities in the subject area, such as Open Days. We set out a framework for the final year students based around UofG's Graduate Attributes, the academic abilities, personal qualities and transferable skills which all students will have the opportunity to develop as part of their University of Glasgow experience. For example, role descriptors addresses these attributes: sound knowledge of subject specialism; expert knowledge of relevant subject/class/session; excellent communication skills;

For the Level 1 student this scheme had the goal to help students adjust quickly to university life; acquire a clear view of course direction and expectations in the DMIS lab sessions; improve their learning skills and adjust their study habits to meet the requirements of higher education; enhance their understanding of the subject matter of their course through collaborative group discussion; and prepare better for assessed work and examinations.

\section{Method}

In order to follow the implementation of the scheme, a survey was carried out over two years 2016/17 and 2018/19 asking both the first year students and the final year students about their experiences. A simple questionnaire was used for the first year students. We set up focus groups throughout the year and carried out a survey of the final year students.

PAL Lab Demonstrators were asked five simple questions with the first three questions having five-point scale (e.g. Likert Scale). These questions were designed to test the graduate attributes we anticipated the final year students gaining after the year's experience. (Keenan 2014)

The survey again for the first year students was based on the five point scale and had five quantitative questions with one open question for qualitative comments. The results were less firmly positive as the final year students but overall the PAL scheme shows an awareness of the scheme and in some cases, highly positive. We had a low response rate to the survey so the results may not indicate any significance. 


\section{Discussion}

The results of 2016/17 survey are encouraging, the results from the 2018/19 feedback show us clearly managed to successfully link and embedded the graduate attributes to the role, and that the students themselves reflected better on the experience. The results from the first year students were mixed, giving us some opportunities for development and to rethink our teaching practices.

After the first survey in 2016/17 we redesigned our training and set up more regular meetings of the group, explained the weekly task in more detail, developed key questions for each lab session and set up an informal mentoring scheme for current final year students to engage with third year students to encourage the uptake of the internship role.

\section{Conclusion and follow on work}

We have learned a significant amount about the teaching methods of our programme that can be effective, ensuring more interactivity in the lab sessions. The results show us convincingly that the employability skills of our final year students are developed and established more confidently in them as a direct result of the PAL Scheme. We will be developing more training and support for the final year students to continue the success for this aspect of the scheme. The first year students will have an additional two classes per semester to embed the theory more fully in the practice for their own critical reflection, thus supplementing the PAL scheme and addressing the issue of variability in final year student as a lab demonstrator.

\section{References}

Fitzsimons, D (2012) Student Peer Learning \& The AALLl Professional Evolution, Equity \& Innovation http://www.aall.org.au/sites/default/files/SSSL\%20Symposium\%202012\%20eBook_0.pdf

Arendale, D. (2014). Arendale, D. R. (2014). Understanding the Peer Assistance Learning model: Student study groups in challenging college courses. International Journal of Higher Education, 3(2), 1-12. International Journal of Higher Education. 3. 1-12. 10.5430/ijhe.v3n2p1.

Keenan, C. (2014) Mapping student-led peer learning in the UK, The Higher Education Academy https://www.heacademy.ac.uk/system/files/resources/peer_led_learning_keenan_nov_14-final.pdf

Watts, H., Mallaris, M. and Billingham, O. (2015) Online Peer Assisted Learning: Reporting on practice, Journal of Peer Learning, Volume 8, Article 8 https://files.eric.ed.gov/fulltext/EJ1076440.pdf 